\title{
Design Dryblock In Digital Thermometer Calibrator Based on Arduino
}

\author{
Ardelina Ramadhani, Endang Dian Setioningsih, Syaifudin \\ Department of Electromedical Engineering Poltekkes Kemenkes, Surabaya \\ Jl. Pucang Jajar Timur No. 10, Surabaya, 60245, Indonesia
}

\begin{tabular}{|c|c|}
\hline Article Info & Abstract \\
\hline $\begin{array}{l}\text { Article History: } \\
\text { Received Sep 9, } 2019 \\
\text { Revised May 20, } 2020 \\
\text { Accepted Jun 11, } 2020\end{array}$ & $\begin{array}{l}\text { The dry block is a versatile temperature calibrator that works with heating. Most of the dry block } \\
\text { using one or more inserts that can be exchanged where the holes are drilled. These holes accommodate } \\
\text { various temperature sensors to be calibrated. diameter hole size in accordance with the temperature } \\
\text { sensor into the test. The device is a very simple way, namely by inserting a thermometer to be } \\
\text { calibrated into a hole that has been provided on the tool and will be compared with LM35 }\end{array}$ \\
\hline $\begin{array}{l}\text { Keywords: } \\
\text { digital body } \\
\text { thermometer }\end{array}$ & $\begin{array}{l}\text { between the thermometer display. This temperature reading and temperature modules have been } \\
\text { compared with a calibrated thermometer in BPFK Surabaya, and the biggest mistake in getting the } \\
\text { smallest is } 0,2 \% \text { and } 0.1 \%\end{array}$ \\
\hline
\end{tabular}

temperature

LM35

dry heating

\author{
Corresponding Author: \\ Syaifudin \\ Department of Electromedical Engineering \\ Poltekkes Kemenkes, Surabaya \\ Jl. Pucang East Jajar No. 10, Surabaya, 60245, Indonesia \\ Email: nyong74@gmail.com
}

This work is an open access article and licensed under a Creative Commons Attribution-Non Commercial 4.0 International License.

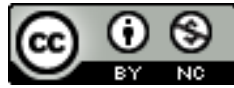

\section{INTRODUCTION}

Dryblock is a versatile temperature calibrator that works by heating, and in many cases cooling, the metal block at a certain temperature and maintain that temperature. Most of the dry block using one or more inserts that can be exchanged where the holes are drilled. These holes accommodate various temperature sensors to be calibrated. diameter hole size in accordance with the temperature sensor being tested.

Dryblock can be designed as a portable or benchtop configuration. Although the specification may vary between models, dry bocks usually offer better accuracy of $\pm 0.5^{\circ} \mathrm{C}$ and range from -25 to $650{ }^{\circ} \mathrm{C}$ temperature uniformity of the hole-to-hole typically $\pm 0.05^{\circ} \mathrm{C}$

Dryblock provide a powerful combination of accuracy, portability, stability, and price. They excel in performing the calibration level playing field or industry in almost all types of temperature sensors, including: thermometer RTD, thermocouple, thermistor, , PRT, bi-metal, etc.

good heat transfer between the insert and the sensor is very important for accurate calibration when using a dry block temperature calibrator. This transfer depends on a very close match between the sensor and the insert. Ideally, there should be no more than a few per thousand licenses in between. Choosing the right inserts to match your sensor is very important. (Total Temperature Instrumentation, Inc. 2018)

Previous dryblock created by Hery Widyanto, 2010. In such a device using a microcontroller and researchers used skin sensors on infant incubator for data retrieval and researchers only use 3 temperature settings, it is ever created by Serly Fitriana Marthasari 2015. In such a device the researchers compared dryblock with waterbath for glass thermometer calibration and dryblock tool on the market that uses a temperature of about - 60 to $2000 \mathrm{C}$ dryblock then have been made by anisa fita 2017 in the tool used to dryblock body thermometer calibrators using Arduino.

\section{MATERIALS AND METHODS}

\section{A. experimental setup}

This study collecting data with a standard thermometer which is done in a room with 4 times the measurement with an interval of 5 minutes.

1) Materials and tools 
This study uses a sensor LM 35 and a spiral-shaped dry heater as a temperature sensor. output sensord subsequently entered and processed into the microcontroller ADC pin.Arduino ATmega 328 as a controller and controller. Output Arduino ATmega328 form on the LCD display 2x16 characters,.

\section{2) Trial}

In this study, researchers conducted a measurement output (mv) on the arrangement between $35-420 \mathrm{C}$ and performing measurements on a set point, display, comparison with multiple-point temperature settings of 36, 38, 39.2, 39.4, 39.8, $40,42$.

\section{B. Block diagram}

First turn on the switch so that the power supply voltage to be supplied throughout the circuit. Enter the temperature setting via the settings button up, down in the temperature range of $35-420 \mathrm{C}$ to a desired temperature. The temperature sensor work to detect the temperature of the heater that was working in the container until the temperature is stable according the selected temperature, and the ADC will change the analog data from the temperature sensor, when the driver heater ON the fan Off, otherwise when the heater OFF the fan is active then the LCD displays the temperature setting accompanied by real temperature to be achieved ..

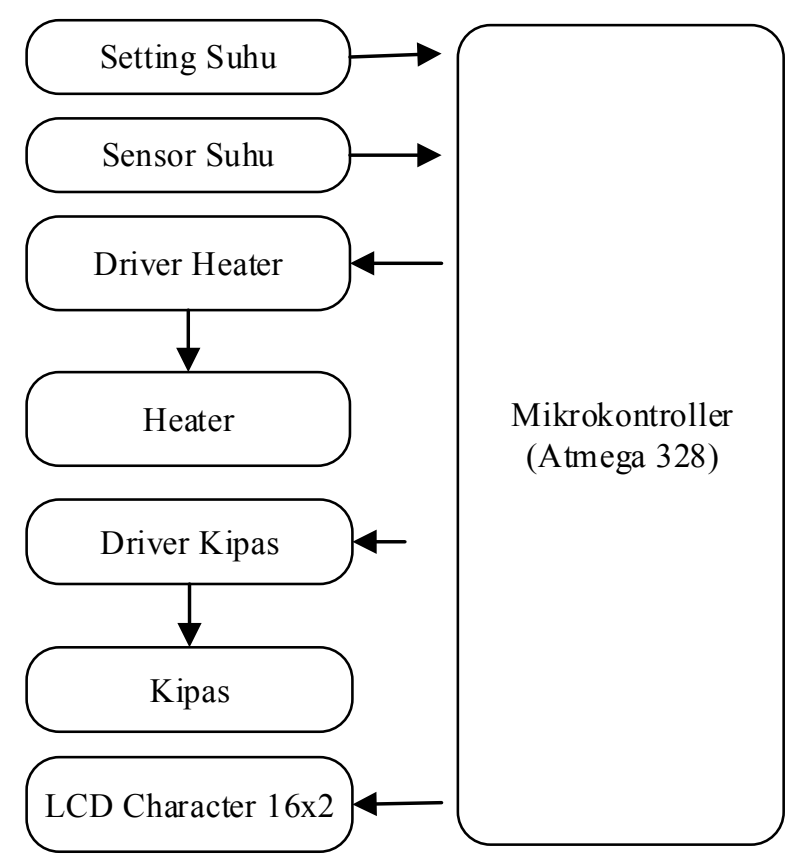

Fig. 1. A block diagram of a Holter monitor

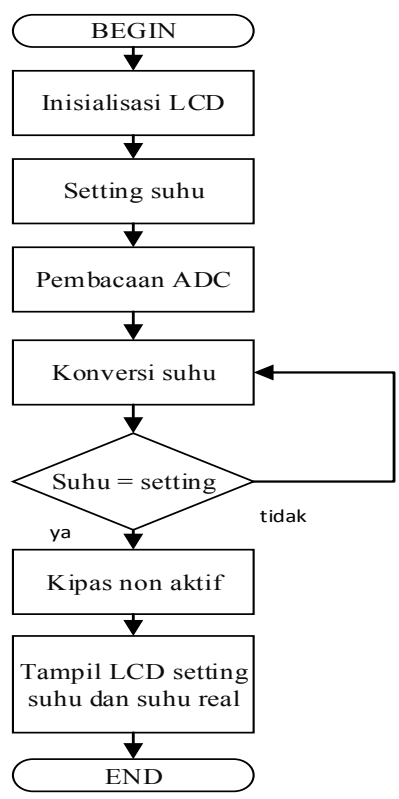

Fig. 2. The Flowchart Program Arduino

\section{The Flowchart}

Press the ON button to start the LCD initialization, and then select the setting temperature at the desired (350C - 420C), the temperature sensor will work in setting the temperature selected, when the temperature sensor On the fan non-active, otherwise when the temperature sensor Off fan will active, then the results from the sensor readings along with the temperature setting is displayed on the LCD ..

\section{Analog circuits}

The important part of this development is an analog circuit that describes in Fig. 3 (driver fans), Fig. 4 (driver heater), and Fig. 5 (temperature sensor), the circuit is used to process dryblock. Therefore it will be ready for digital processing using Arduino.

\section{1) driver Blower}

Specifications blower module NPN transistor driver circuits Using a blower driver. Requires 12 VDC input voltage. Connected to pin D2.

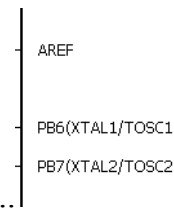

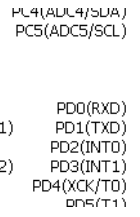

\section{2) heater driver}

Specifications heater driver circuit modules are: Using the SSR for heating driver, Requires 5 VDC input voltage, is connected to pin D3. 

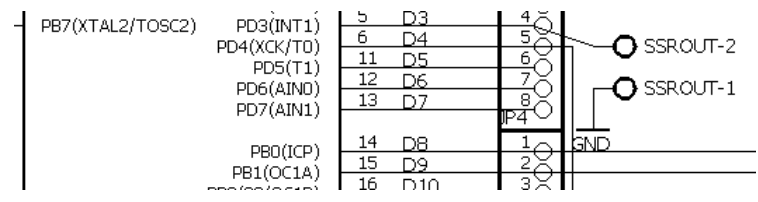

Fig. 4. Heating driver.

3) temperature sensor circuit

Specifications module temperature sensor circuit is: Using LM35 as temperature sensor. Requires 5 VDC input voltage. Connected to the pin A0. temperature sensor circuit is designed as shown in Fig. 5.

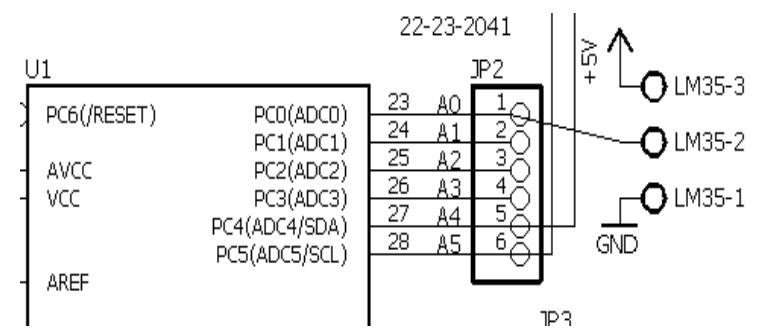

Fig. 5. The temperature sensor circuit.

\section{RESULT}

Research has conducted trials on dryblock tool directly by means of comparison with standard tools.

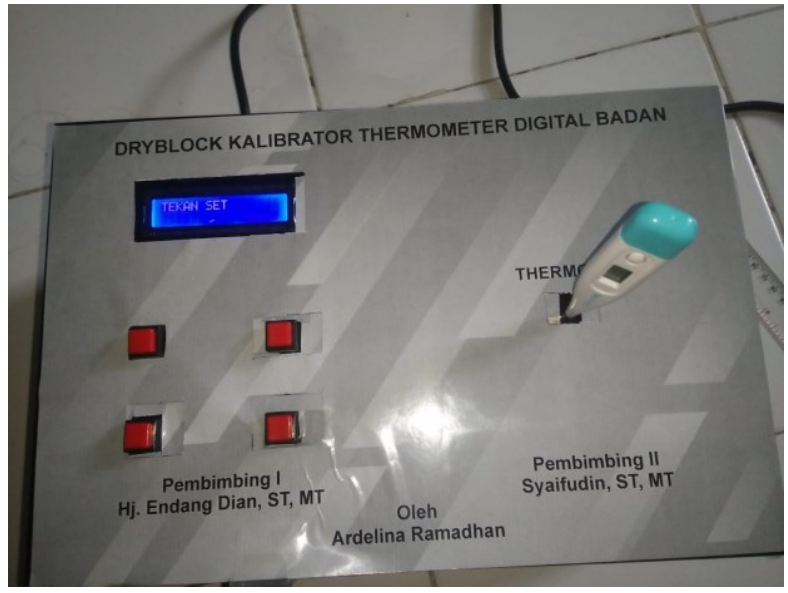

Fig. 6. The Dryblock Calibrato design

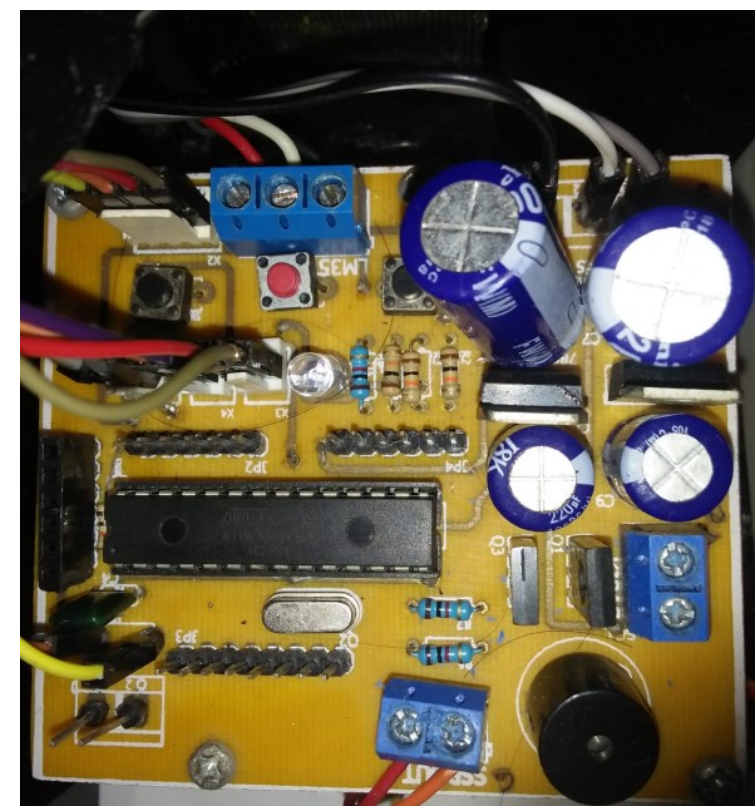

Fig. 7. Digital part of the calibrator dryblock

1) The calibrator dryblock Design

microcontroller circuit as shown above to get the input supply 5 volts and 12 volts which is connected to the sensor LM35 also fan

Program Listings for set point

Once the tool ON initial display on the LCD at the coordinate $(0,0)$ is "TEKANSET", then press ok / enter it will show "SET TEMP" to start the election at this point how the desired temperature in the calibration.

In the tool sets the starting point of the point of $350 \mathrm{C}$ to $420 \mathrm{C}$, with an increase of 0.1 plus minus one digit after the decimal point. , Program Listing is shown as Program Listing 1

1. The program listing for the program set point

void loop () \{
btokx = digitalRead (btok);
lcd.setCursor (0.0);
lcd.print ( "PUSH SET");
if (btokx == HIGH) \{
lcd.clear ();
delay (1000);
setsuhu ();
start ()$;$
\}
\}




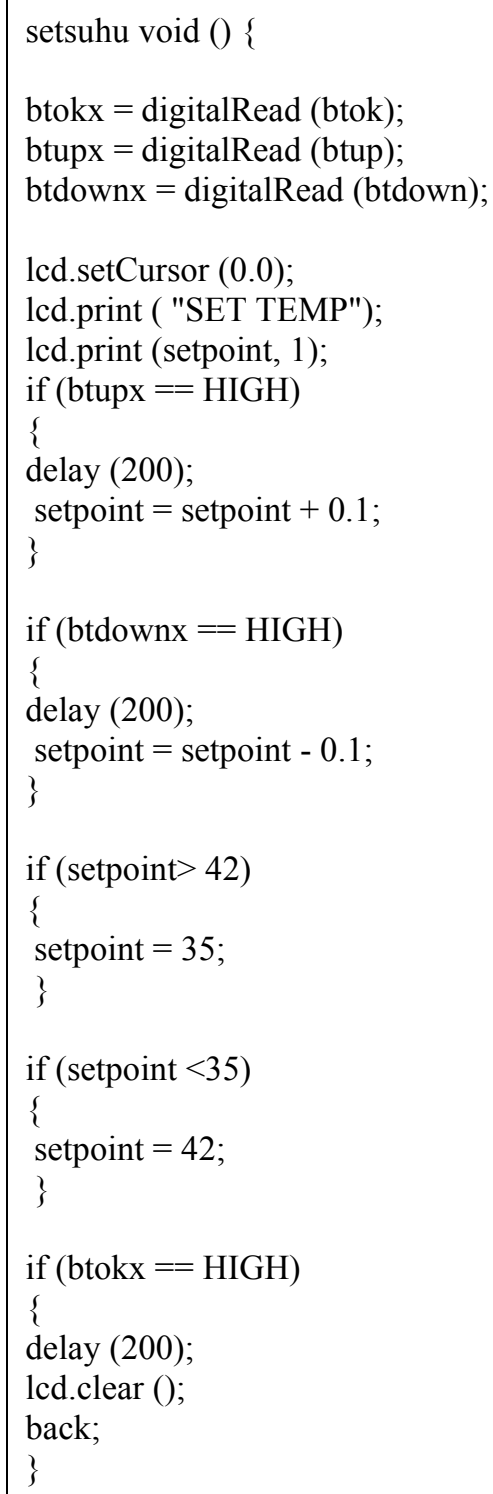

LM35 subprograms above formula is used in the conversion of the output voltage of the LM35 is in the form of the Volt in degrees Celsius. Program Listing is shown as Program Listing 2.

Listing Program 2. Program for for LM35

adclm $=$ analogRead (A0);

Temperature $=(\operatorname{adclm} *(5.0 / 1023.0) * 100)$;
Heating control is pid and pid will work on a range of 0 to 255 , if pid is less than 1 then pid still will show 0 and if pid is more than 255 then pid will still show the 255 , it aims to limit if the event pid number (-) or above 255 , and the program list that is used to open the ECG signal is recorded shows in program listings 3.

Program listing 3. PWM or heating program

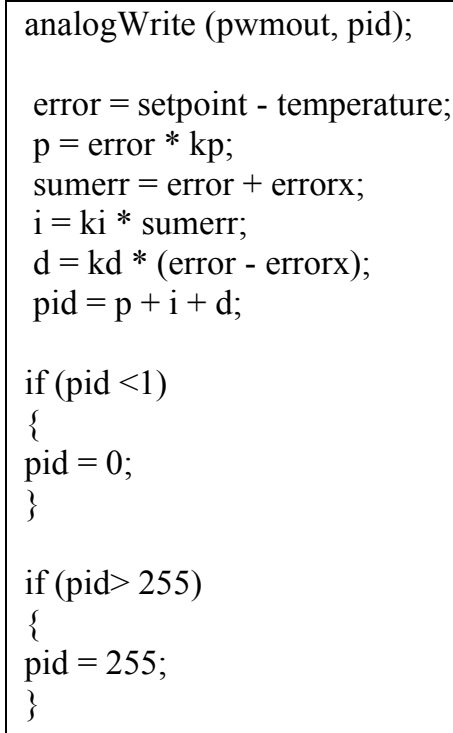

5) Recording Program Fan

Fans will work if the temperature is more than a set point, and will die if the temperature is still in the achievement setting.and temperature program used to open a list of the ECG signal is recorded shows in Program Listing 4.

Fan 4. Program list Program

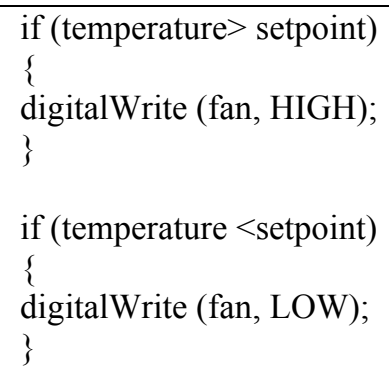

6) Program Listing shows the LCD screen

On the LCD screen will display "SP" "P" at the coordinates $(0,0)$ where SP is the set point, $\mathrm{P}$ is pid, and "T" "Er" at 
coordinates $(0.1)$ where $\mathrm{T}$ is the room temperature detected by the sensor LM35 and Er is an error. and a program list that is used to open the ECG signal is recorded shows in Program Listing 4.

Listing Program 4. The program shows the LCD screen

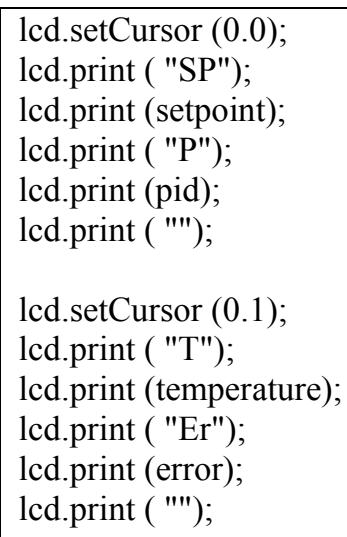

\section{7) The results of measurements on voltage output $35 \mathrm{~lm}$}

Validation BPM value displayed in the Delphi programming compared with pulse oximetry devices. The mistake was demonstrated in Table I.

TABLE I. 35 LM OUTPUT VOLTAGE.

\begin{tabular}{lcc} 
no & Setting Temperature $\left({ }^{\circ} \mathrm{C}\right)$ & $\begin{array}{c}\text { Sensor Output } \\
\text { Voltage }(\mathrm{V})\end{array}$ \\
\hline 1 & 35 & $0: 34$ \\
\hline 2 & 36 & 0.35 \\
\hline 3 & 37 & 0.36 \\
\hline 4 & 38 & 0.37 \\
\hline 5 & 39 & 0.38 \\
\hline 6 & 40 & 0.39 \\
\hline 7 & 41 & $0: 40$ \\
\hline 8 & 42 & 0.41
\end{tabular}

TABLE II. MEASUREMENT ERROR FOR DRYBLOCK THERMOMETER CALIBRATORS

\begin{tabular}{ccc} 
& $\begin{array}{c}\text { Setting } \\
\text { Temperature }\left({ }^{\circ} \mathrm{C}\right)\end{array}$ & Error $\left({ }^{\circ} \mathrm{C}\right)$ \\
\hline 1 & 36 & 0.54 \\
\hline 2 & 38 & $0: 59$ \\
\hline 3 & 39.2 & 0.52 \\
\hline 4 & 39.4 & 0.23
\end{tabular}

\begin{tabular}{ccc}
5 & 39.8 & 0.14 \\
\hline 6 & 40 & $0: 34$ \\
\hline 7 & 42 & 0.68
\end{tabular}

Dry block calibrator measurement results are shown in Table 2.

\section{DISCUSSION}

Based on the above voltage measurements can be analyzed that the output of each setting temperature close to the temperature setting in because the value of the temperature sensor tolerance

The measurement results displayed on dryblock appliance thermometer calibrators compared with the error value in a can set the temperature $360.1 \% 380.1 \%$ temperature temperature temperature $39.4 \quad 39.2 \quad 0.1 \% \quad 39.8 \quad 0.1 \%$ at $0,2 \% \quad 0.2 \% \quad 40$ temperature and a temperature of $420.1 \%$..

\section{CONCLUSION}

Based on the results of the discussion and the destination can be concluded that the module can be made digital thermometer calibrators dryblock media agency with a temperature setting between $35-420 \mathrm{C}$ resolution of 1 digit after the decimal point, and measurements that have been carried out concluded that the sensor that can affect error.

\section{REFERENCE}

[1] Total Temperature Instrumentation, Inc. (2018) 'Dryblock'. Retrieved Retrieved on September 30, 2018, 23:00 pm

[2] 'Books engin e er Note this' (no date), p. 1470. Accessed at Retrieved on September 30, 2018, 23:00 pm

[3] Ii, Chapter and Council, USA (2005) 'Heat Proukdi', pp. 7-19. Retrieved Retrieved on September 30, 2018, 23:00 pm

[4] ISO / IEC Guide 17025 (2005) 'Calibration' Retrieved Retrieved on September 30, 2018, 23:00 pm

[5] Microcontroller, L. (2013) 'laboratory material'. Surabaya. Retrieved Retrieved on September 30, 2018, 23:00 pm

[6] Solomon, C. \& kusnadi (2011) 'PT100 and Thermocouple Temperature Calibration' Elite Electro Scientific Journal, 2 (2), p. 99-104. Retrieved Retrieved on September 30, 2018, 23:00 pm

[7] Thermometer, J., On, TD and Bellani, S.- (2012) 'Various thermometer'. Retrieved Retrieved on September 30, 2018, 23:00 pm

[8] North, USA (2005) 'CHAPTER II LITERATURE REVIEW 2.1 Production of X-rays', pp. 5-16. Retrieved Retrieved on September 30, 2018, 23:00 pm. 